\title{
IDENTIFICAÇÃO E AVALIAÇÃO DAS UNIDADES PAISAGÍSTICAS NO SUBDISTRITO BUTANTÃ
}

\author{
Ana Cristina Gaspar \\ Licenciatura em Ciências da Engenharia do Ambiente pela FCT-UNL. Mestranda em Engenharia do \\ Ambiente pela FCT-UNL - E-mail: ac.gaspar88@gmail.com
}

\begin{abstract}
Resumo
O presente artigo faz uma avaliação das unidades paisagísticas no Subdistrito Butantã com o objectivo de oferecer melhores bases de planeamento para futuros projectos e planos. Da realização deste trabalho salienta-se a importância da utilização de SIG que facilitam a interpretação dos dados e diminuem o tempo despendido na sua avaliação. Da conclusão da identificação e avaliação das unidades paisagísticas evidencia-se a importância que a Cidade Universitária tem no subdistrito e o maior potencial de protecção da paisagem local que esta unidade apresenta. Quanto ao potencial de urbanização, é a unidade "Residencial vertical - fundo de vale" que adquire um valor mais elevado.Assim, estas unidades devem admitir uma correcta gestão, beneficiando a qualidade de vida da população residente e contribuindo para a diminuição dos problemas de uma rápida expansão urbana e sem planeamento.
\end{abstract}

Palavras-chave: avaliação da paisagem, crescimento urbano, paisagem, potencial de protecção da paisagem local, potencial de urbanização, Subdistrito Butantã, unidades paisagísticas. 


\title{
IDENTIFICATION AND EVALUATION OF LANDSCAPE UNITS IN BUTANTÃ SUBDISTRICT
}

\begin{abstract}
This article assesses the landscape units in Subdistrict Butantã in order to provide better basis for planning future projects and plans. Of this study highlight the importance of using GIS to facilitate the interpretation of the data and decrease the time spent in the evaluation.Completion of the identification and assessment of landscape units highlights the importance the University City is in the subdistrict and the greater potential for protection of local landscape features that this unit. As for the potential of urbanization, the unit is "Vertical Residential - valley bottom" that acquires a higher value. Thus, these units must admit a proper management, enhance the quality of life of residents and contributing to reducing problems of rapid urban expansion and unplanned.
\end{abstract}

Keywords: assessment of landscape,urban growth, landscape, potential protection of the local landscape, potential of urbanization, Subdistrict Butantã, landscape units.

\section{INTRODUÇÃO}

O crescimento acentuado de uma metrópole acarreta consequências para todo o sistema natural e urbano da região, que necessitam de ser preferencialmente evitados ou, posteriormente, mitigados. A cidade de São Paulo sofreu uma rápida expansão urbana, que pôs em causa a evolução saudável da paisagem.

Neste âmbito, o presente artigo pretende identificar e avaliar as unidades paisagísticas doSub-distrito Butantã de modo a contribuir para um melhor conhecimento da paisagem da zona, tendo em vista futuras intervenções.

Actualmente, o facto de haver uma multiplicidade de matérias teóricas e práticas sobre a paisagem e a sua avaliação, leva a uma ausência de consenso e sistematização ao nível de conceitos e metodologias. Assim, as diferentes definições de paisagem reflectem a diversidade de disciplinas que abordam esta temática mas que, simultaneamente contribuem para a sua evolução e dificuldade de interpretação. 
(...) qualquer paisagem invoca diversas memórias e associações na mente humana, pelo que a palavra em si mesma implica diferentes significados. (Lyle, 1999)

Assim como Lyle (1999),Barreiros(2005) e Magalhães(2007) também defendem que a paisagem é um objecto de estudo no qual os profissionais identificam a matéria mais interessante para investigar. Deste modo, torna-se complicado e mais complexo atribuir uma única definição que esteja em concordância com as premissas de todos os que estudam e se interessam por esta matéria. Forman e Godron (1986) afirmam que uma paisagem é caracterizada como "uma unidade distinta e mensurável, definida pelo seu padrão de agrupamentos de ecossistemas em interacção, desenvolvimento geomorfológico, regimes de perturbação e evolução".

Neste sentido, Barreiros (2005) esquematizou o conceito de paisagem (Figura 1) como sendo sistemas não herméticos, existindo constantes transferências e em evolução.

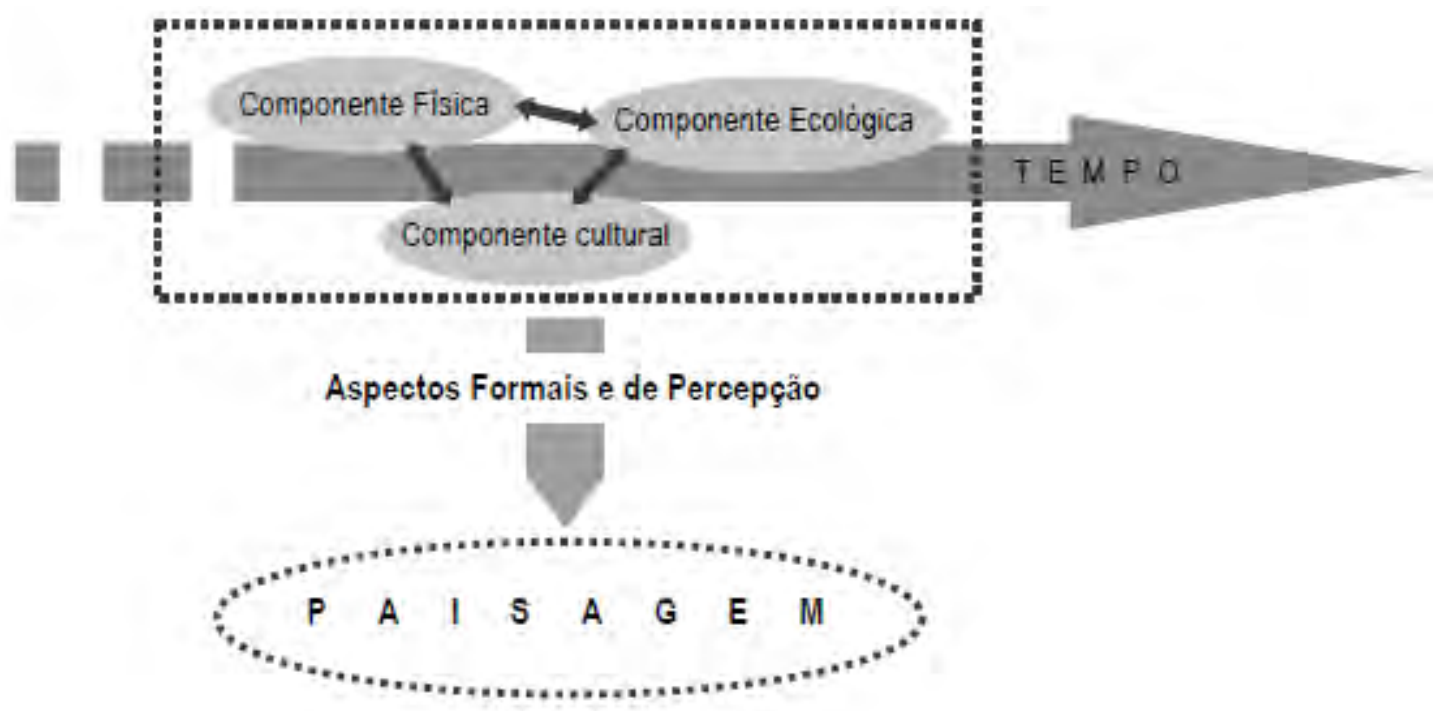

Figura 1: representação esquemática da abordagem conceptual de Paisagem. Fonte: Barreiros, 2005

Da figura anterior verifica-se que fazem parte de uma paisagem as componentes físicas do próprio sistema ecológico e cultural. São estas componentes que permitem que a paisagem adquira uma identidade e especificidade, de onde fazem parte as componentes internas e externas. No entanto, todas estas características são únicas do indivíduo que a vivencia e, por isso, a paisagem nunca será entendida e vista de igual forma, por duas pessoas. 
Já Magalhães (2007) afirma que uma paisagem não é mais do que o arranjo espacial dos elementos constituintes de uma paisagem - o mosaico.A autora também defende que a paisagem pode ser reconhecida como as apropriações e transformações operadas no passado. Assim, os elementos constituintes da paisagem devem assumir um carácter mais permanente, devendo-se evitar a sua deterioração sob o risco de estes se perderem de uma forma definitiva.

Assim, é importante reconhecer que, actualmente, a paisagem já não é entendida como um sistema com fronteiras estanques, e que não se concebe por meio das dualidades que caracterizam a típica divisão de natureza vs cultura, cidade vs campo ou paisagem vs arquitectura. A abordagem de que a paisagem tem um carácter dinâmico, não sendo um realidade estática é importante, devido às transformações que esta pode sofrer ao nível da organizaçao espacial dos elementos que a compõem (Magalhães, 2007).

A função principal da paisagem é o fluxo de pessoas, animais, materiais, energia, água e plantas. Neste âmbito, a utilização de um Sistema de Informação Geográfica (SIG) é fundamental pois permite entender a relação entre os elementos da paisagem e as suas influências. A incorporação do conhecimento da ecologia com o planeamento da paisagem contribuem para uma abordagem de um planeamento da paisagem. Para além disso, o conhecimento sobre o tema e os métodos e técnicas de planeamento devem ser aplicados a todas as actividades humanas. Sendo assim, é possível afirmar que a paisagem é um fenómeno complexo, sendo constituída por uma área relativamente homogénea no que respeita à forma e processos activos (unidades paisagísticas).

Do ponto de vista estrutural, todas as paisagens são constituídas por três elementos universais, que se articulam através de processos naturais e da utilização que deles fazem os grupos humanos: matriz, machas e corredores. Ainda é possível referir as bordas- estrutura que é capaz de ligar todos os outros elementos e só se conserva através do contacto entre eles. Assim, a borda corresponde a uma porção da mancha, corredor ou matriz onde o ambiente difere significativamente a partir do interior. Logo, se há uma maior diversidade estrutural (diferentes alturas e tipos de vegetação), as bordas também podem ter uma maior diversidade (Center, 2010). 
De acordo com Forman e Godron(1986)e Harris eGallagher(1989)inJack(1995) o futuro das paisagens passa por conceberestrategicamente uma estrutura com manchas, corredores e steppingstones de modo a conectar as manchas isoladas e reverter os efeitos da fragmentação.

Neste sentido, e de acordo com os mesmos autores, a textura - organização espacial que gera um arranjo espacial - expressa-se por um arranjo repetitivo formado pelo mosaico de manchas e os seus corredores, dispostos numa matriz de fundo(Forman \& Godron, 1986). Já Magalhães (2007) afirma que a estrutura de uma paisagem consiste num padrão das distribuições dos elementos e esse mesmo padrão da paisagem influencia os processos ecológicos e as suas características. Esses elementos têm a capacidade de se relacionar e interligar, avançando e recuando, nunca havendo término nessa evolução. Por isso, a estrutura da paisagem tem uma relação estreita com a abundância do biótopo e da sua diversidade.

De acordo com Forman e Godron (1986) existem três características que compõem a paisagem:

$\checkmark \quad$ Estrutura: é o produto do relacionamento espacial entre os distintos ecossistemas ou elementos presentes. Ou seja, é o arranjo ou padrão espacial da paisagem seja tamanho, forma ou número e tipo de configurações dos ecossistemas.

$\diamond \quad$ Função: caracteriza-se pelas interacções entre os elementos espaciais, representados pelos fluxos de energia, materiais e espécies entre os ecossistemas que fazem parte de uma paisagem.

$\diamond \quad$ Mudança: é dada pela alteração na estrutura e na função do mosaico ecológico através de um horizonte temporal.

Zonneveld (1979) in Filho (1998) é o primeiro a definir unidade de paisagem como sendo um conceito fundamental na Ecologia da Paisagem.

Uma unidade de paisagem, sendo um conjunto tangível de relacionamentos internos e externos, fornece as bases para o estudo das inter-relações topológicas e corológicas.

Zonneveld (1979) in Filho(1998) 
Segundo o mesmo autor, a unidade de paisagem é a expressão da paisagem de acordo com uma visão sistémica, podendo ser definida como um extensão de superfície da Terra ecologicamente homogéneo a uma certa escala de interesse. O termo homogéneo é utilizado na sua definição e significa que os gradientes internos não podem ser distinguidos ou então possuem um padrão distinto em relação às unidades vizinhas. De acordo com Forman e Godron (1986), o fragmento mais homogéneo, dentro de um elemento de paisagem heterogéneo é denominado de tessela (tesserae), representando a menor unidade homogénea visível na escala espacial de uma paisagem.

A definição de unidade de paisagem tem como base as características mais perceptíveis num mapeamento como o relevo, a litologia, o clima, o solo, a estrutura ecológica, a vegetação e as alterações antrópicas. Esta análise multifacetada permite a compreensão da paisagem e a sua melhor análise. Os autoresCastro e Lopes(2009) identificam os factores que estão na origem da formação da paisagem, visualizada na Figura 2.

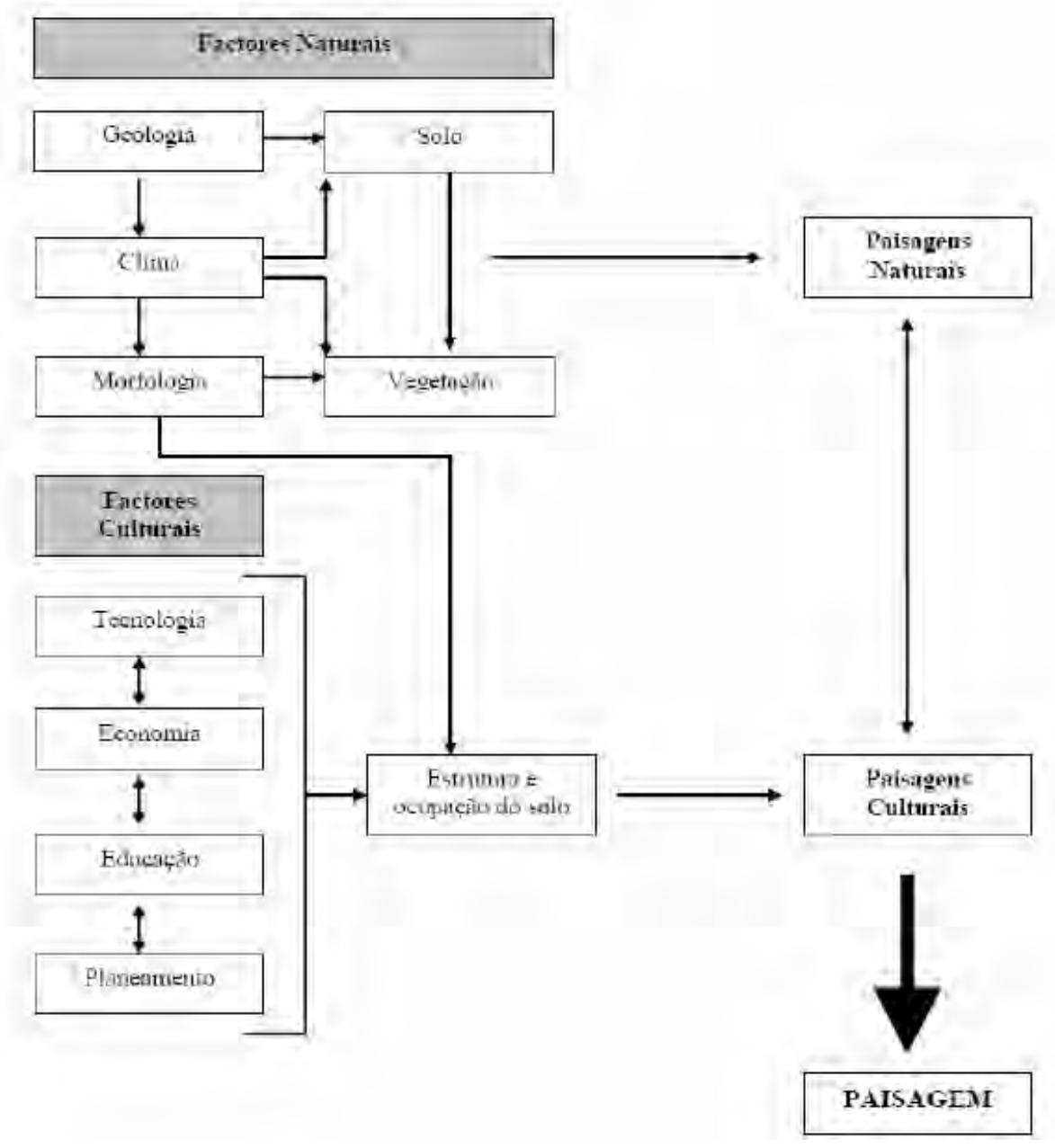

Figura 2: relação entre os principais factores determinantes da paisagem. Fonte: Castro e Lopes, 2009 
Como se observa pela figura anterior, existe um contributo dos factores naturais e culturais que formam as paisagens naturais e culturais. Da combinação destas duas paisagens resulta a paisagem em si, composta pela estrutura e ocupação do solo e a vegetação/ solo.

\section{CARACTERIZAÇÃO DA ÁREA DE ESTUDO}

As metrópoles são o resultado de um desenvolvimento urbano fruto dos impactes da evolução da industrialização Bruna, Goldemberg e Roméro (2000) e após séculos de urbanização centrada no litoral, o Brasil começou a mostrar sinais de mudança. Segundo Maricato (2006) em 1970, o Brasil tinha cinco metrópoles com mais de 1 M de hab e, de acordo com Filho, Barros, Hallak, e Gandú (2004), a Região Metropolitana de São Paulo (RMSP) é a maior área urbana brasileira onde tem havido uma degradação ambiental significativa.

Segundo Tucci (2005) este crescimento urbano tem-se dado principalmente nos países em desenvolvimento de uma forma insustentável. Como consequência existe uma deterioração da qualidade de vida e do meio ambiente. No Brasil, a população urbana é de $77 \%$ ( $47 \%$ da população total do globo), o que agrava ainda mais os problemas das grandes metrópoles. Como o planeamento urbano é realizado para as áreas da cidade ocupadas pela população de renda média e alta, existe uma ocupação sobre as áreas de risco por parte da população de baixo rendimento.

A criação das metrópoles no Brasil veio a concretizar-se devido a variados factores como a descentralização da indústria, a expansão do agronegócio e da exploração de minérios e madeira. Neste âmbito, a Região Metropolitana de São Paulo (RMSP), em 2002, era responsável pela $23 \%$ da produção industrial do país (Maricato, 2006).

A RMSP é constituída pelo Município de SP e mais 38 municípios, que se agrupam em torno da capital do Estado e, foi criada pela Lei complementar número 14 de 08 de Junho de 1973, sendo que actualmente é composto por quinze Regiões Administrativas. Estes 39 municípios que integram a RMSP representam 3,24\% do total do território do Estado, numa área de $8,051 \mathrm{~km} 2$, concentrando $48,04 \%$ da população de todo o Estado (Bógus \& Pasternak, 2009). 
O distrito do Butantã, localizado no extremo oeste de São Paulo, possui uma área aproximada de $12,5 \mathrm{~km}^{2}$ e é constituído pelos Subdistritos Butantã. Rio Pequeno, Vila Sônia, Morumbi e Raposo Tavares, tal como identificado na seguinte figura. É o Susbdistrito Butantã que será o objecto de estudo deste artigo.

\section{Subdistritos de Butantã}

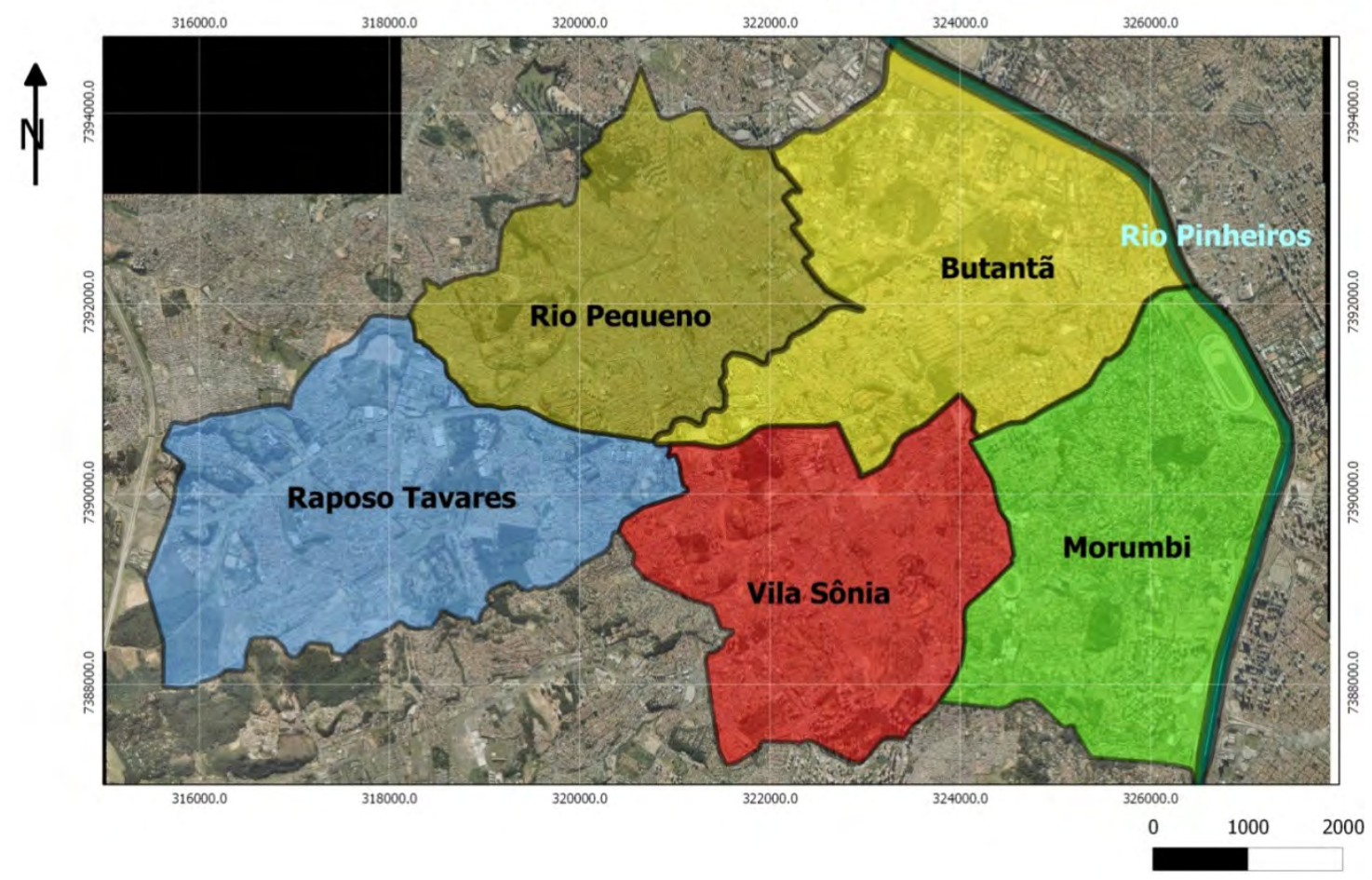

Figura 3: subdistritos presentes no distrito de Butantã. Bases: CEM e Emplasa (ortofotomapas 1:5000 de 2007).

\section{MATERIAL E MÉTODOS}

Tendo em conta o desenvolvimento das unidades paisagísticas presentes no subdistrito Butantã foi desenvolvida a metodologia apresentada na figura 4. Esta metodologia divide-se em três fases que apresentam a respectiva explicação seguidamente. 


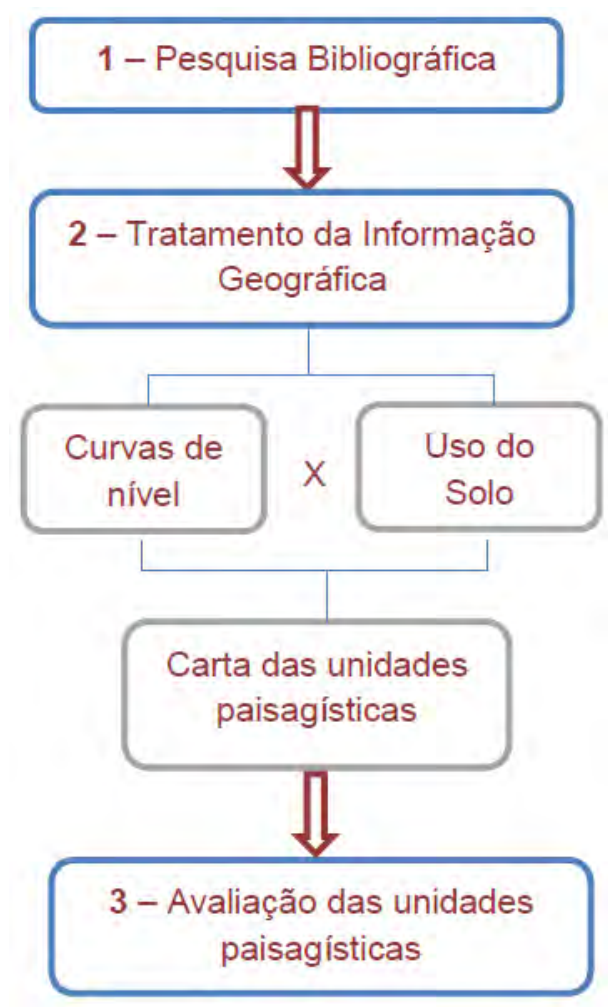

Figura 4: metodologia utilizada

\section{Pesquisa bibliográfica, definições e conceitos}

Numa primeira fase procedeu-se à pesquisa bibliográfica, caracterizada por ser uma etapa teórico-conceitual, onde foram definidos os objectivos do presente trabalho. Depois de se definir os conceitos-chave para a total percepção do artigo, efectuou-se uma pesquisa sobre a região e o Subdistrito Butantã. Esta informação foi disponibilizada, maioritariamente, no site da subprefeitura de Butantã e pelo Google Earth.

\section{Tratamento da Informação Geográfica}

Para o tratamento da informação geográfica recorreu-se ao software QGIS (1.7.4), a ortofotomapas de 2007, ao Google Earth e a informação disponibilizada pelo CESAD e pelo CEM (Centro de Estudos da Metrópole).O CESAD disponibiliza informação fornecida pela Emplasa, CDHU (Companhia de Desenvolvimento Habitacional e Urbano) eo sistema de coordenadas utilizado foi o SAD 69/ UTM zone 23S. 


\subsection{Carta do uso do solo}

Identificação do uso do solo a partir da informação disponibilizada pelos ortofotomapas 1:5000 de 2007, da Emplasa, Carta de Uso do Solo Predominante de 2005 da Subprefeitura do Butantã e do Google Earth.

\subsection{Carta das unidades paisagísticas}

Para a obtenção da informação relativa às unidades paisagísticas foi cruzada a informação das curvas de nível e do uso do solo do subdistrito Butantã. Para tal, recorreuse a ferramentas de geoprocessamento do software QGIS (1.7.4) que foram, posteriormente, interpretadas.

\section{Avaliação das unidades paisagísticas}

Nesta etapa, foi desenvolvida uma avaliação às unidades identificadas na fase anterior através da realização das tabelas de atribuição de valores para uso urbano e atribuição de valores para a conservação da paisagem. As tabelas apresentadas nesta fase foram fornecidas pela disciplina Planejamento da Paisagem - AUP-062,.

\section{RESULTADOS E DISCUSSÃO}

A realização deste artigo originou a realização de cartas essenciais para a elaboração de trabalhos futuros no subdistrito Butantã. A figura seguinte mostra a primeira carta utilizada para a formação das unidades paisagísticas e representa as curvas de nível presentes neste subdistrito. 


\section{Curvas de nível do Subdistrito Butantã}

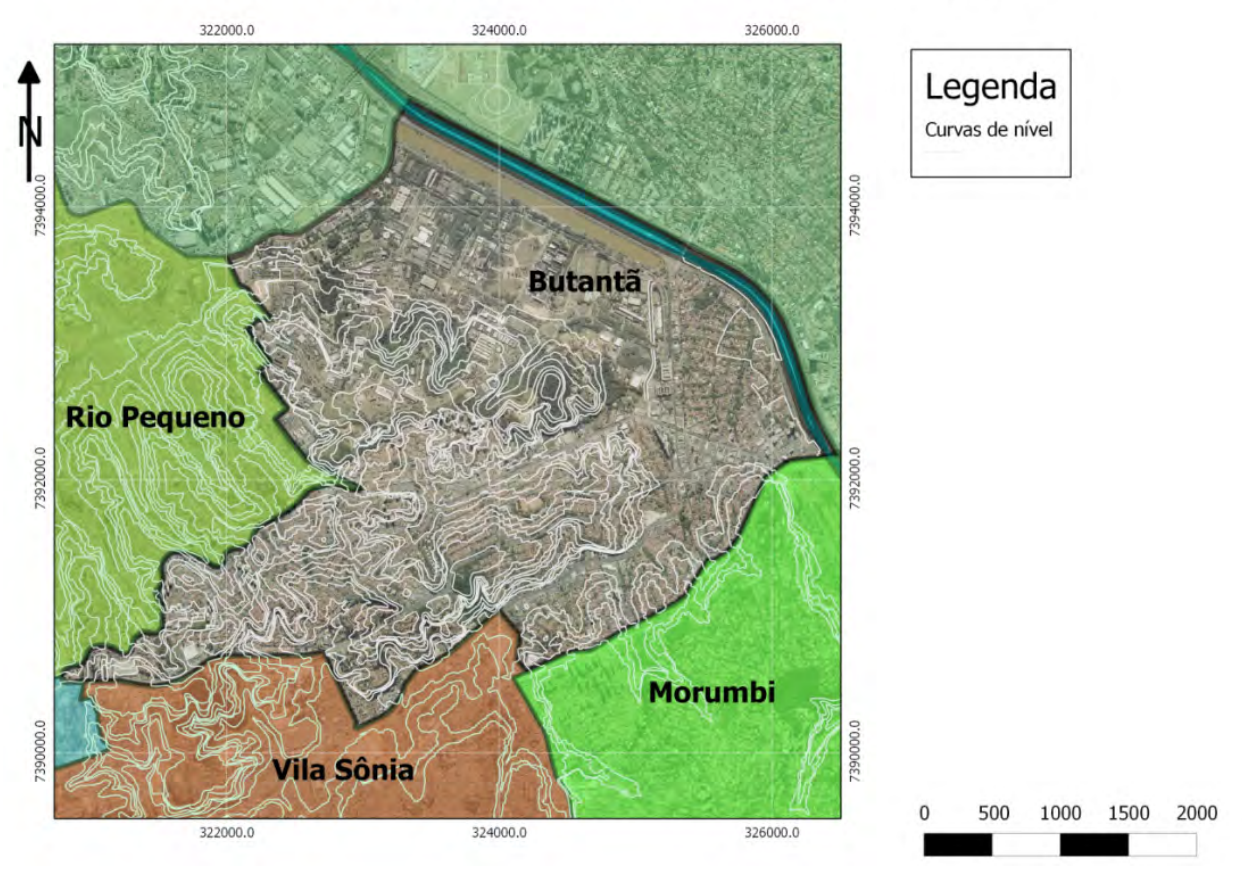

Figura 5: curvas de nível do Subdistrito Butantã. Bases: Emplasa (ortofotomapas 1:5000 de 2007) e CEM.

Pela figura observa-se que a Cidade Universitária, situada a norte de Butantã, apresenta um declive relativamente baixo, ao contrário na zona Sul do Subdistrito. Verificou-se que as curvas de nível variam entre $720 \mathrm{~m}$ a $805 \mathrm{~m}$ dentro da área estudada e que esta apresenta pouca homogeneidade relativamente a este parâmetro.

A carta de Uso de Solo do Butantã está representada na figura 6 e foram observados doze diferentes usos para o Subdistrito estudado. 


\section{Uso do Solo do Subdistrito Butantã}
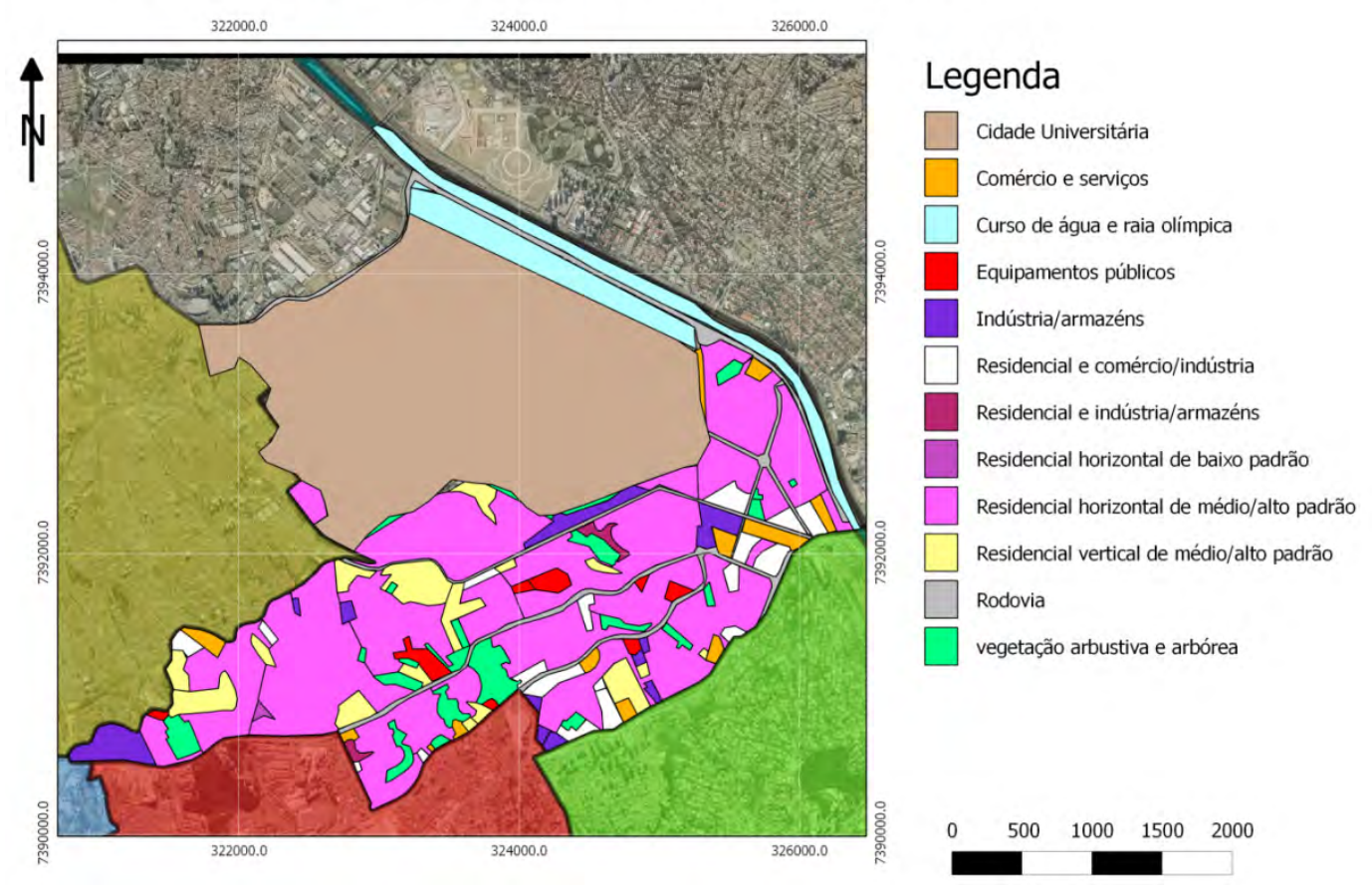

Figura 6: uso do Solo do Subdistrito Butantã. Bases: Carta de Uso do Solo Predominante de 2005 da Subprefeitura do Butantã, Empala (ortofotomapas 1:5000 de 2007).

Observa-se que existe uma predominância de residências horizontais de médio/alto padrão neste subdistrito e apenas uma região encontrada que se caracterize por ser um conjunto de residências horizontais de baixo padrão. As rodovias são evidenciadas por fazerem a ligação de Este a Oeste, funcionando como corredores. O Rio Pinheiros (curso de água) mostra-se como uma das limitações do Butantã, a nordeste, acompanhando a marginal Pinheiros.

O uso do solo que mais se destaca é a Cidade Universitáriaque ocupa toda a região norte. Mesmo sendo uma mancha compacta, a Cidade Universitária contém outros usos, dentro dela. Assim, para a Cidade Universitária funcionar apenas como uma única mancha, não foram incluídas e avaliadas os restantes usos dentro desta área. Existe, portanto uma percentagem de vegetação arbustiva e de rodovias que não foram incluídas nesta avaliação para não retirar percentagem de ocupação da mancha Cidade Universitária. No entanto, são se pode deixar de referir a grande percentagem de vegetação arbórea e de rodovias presentes neste tipo de uso do solo. 
A mancha caracterizada por ser vegetação arbustiva e arbórea aparece pontualmente, sendo que não apresenta uma grande abundância neste subdistrito. No entanto, à escala utilizada não foi possível ter em conta todo tipo de vegetação (incluindo rasteiras e herbáceas) e toda a vegetação presente em ruas e estradas.

A figura seguinte representa o cruzamento da informação dos usos do solo observados e das curvas de nível defundo de vale, encosta e topo de morro, originando assim a carta das unidades paisagísticas presentes neste subdistrito.

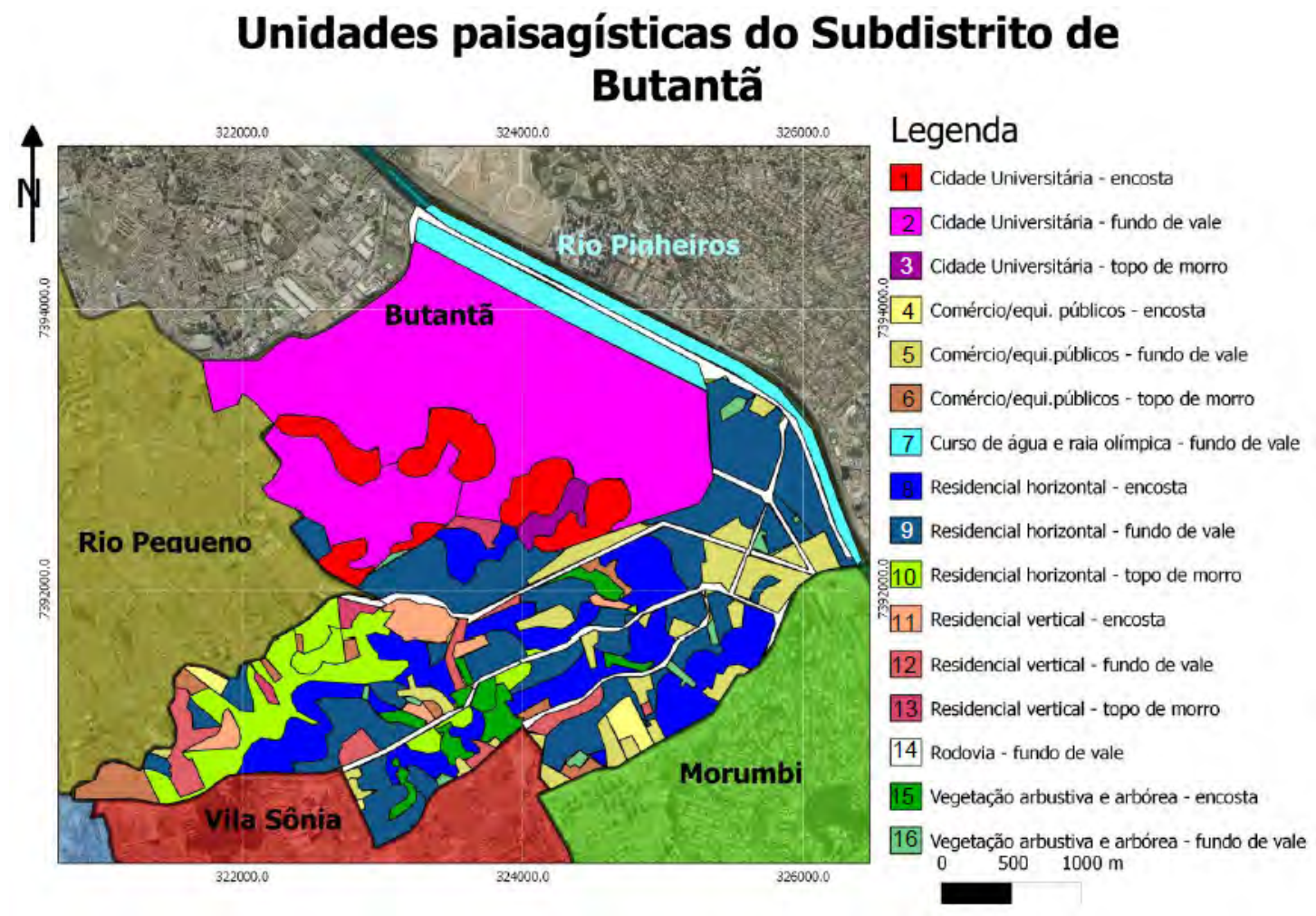

Figura 7: unidades paisagísticas no Subdistrito Butantã. Carta de Uso do Solo Predominante de 2005 da Subprefeitura do Butantã, Empala (ortofotomapas 1:5000 de 2007).

Para a melhor percepção das unidades paisagísticas foram combinadas alguns usos do solo identificados na figura 6. Assim, o uso "residencial horizontal de baixo padrão" e "residencial horizontal de médio/alto padrão" sofreram uma junção, tal como "indústrias e armazéns", "comércio e serviços" e "equipamentos públicos".

Como se pode observar pela figura anterior a unidade paisagísticas mais expressiva continua a ser a cidade universitária com características de fundo de vale. A unidade "Cidade Universitária - encosta" está localizada nas zonas de vegetação intensa identificada e referida anteriormente, mas ausente na carta de usos do solo. É de sa- 
lientar que a rodovia foi sempre construída em fundo de vale, ao contrário de todas as outras unidades identificadas. Como era de esperar, o curso de água e a raia olímpica situam-se em declives baixos e não existe nenhuma vegetação arbustiva e arbórea em topo de morro (excepto a da Cidade Universitária e que não foi contabilizada).

Para a avaliação das unidades paisagísticas foram completadas as tabelas seguintes, relativas ao uso urbano (tabela 1) e à paisagem local (tabela 2). Relativamente ao peso atribuído, o menor (valor nulo) quer dizer que não existe a característica estudada, e o máximo (um, dois ou três) a sua presença.

\begin{tabular}{|c|c|c|c|c|c|c|c|c|c|c|c|c|c|c|c|c|c|}
\hline \multicolumn{18}{|c|}{ Atribuição de valores para uso urbano } \\
\hline \multirow[t]{2}{*}{ Peso } & \multirow[t]{2}{*}{ Característica } & \multicolumn{15}{|c|}{ Unidades de Paisagem } & \multirow[b]{2}{*}{16} \\
\hline & & 1 & 2 & 3 & 4 & 5 & 6 & 7 & 8 & 9 & 10 & 11 & 12 & 13 & 14 & 15 & \\
\hline $0-2$ & $\begin{array}{l}\text { Inexistência de restrição ambiental (aptidão para } \\
\text { urbanização) }\end{array}$ & 0,5 & 0,7 & 1 & 0,5 & 1,3 & 1,7 & 0 & 1,2 & 1,5 & 0,6 & 0,8 & 1,3 & 0,8 & 0,2 & 0,8 & 0,9 \\
\hline $0-2$ & Potencial para expansão urbana & 0,1 & 1,1 & 0,7 & 0,7 & 1,6 & 0,9 & 0,3 & 0,5 & 1,5 & 1 & 1,2 & 0,7 & 1,5 & 1,8 & 0,5 & 0,9 \\
\hline $0-2$ & $\begin{array}{l}\text { Contiguidade a áreas urbanizadas e vectores de } \\
\text { urbanização }\end{array}$ & 0 & 1,2 & 0 & 0,2 & 1,6 & 0,1 & 0 & 1,6 & 1,7 & 1,1 & 1,5 & 1,8 & 1,8 & 2 & 0 & 0 \\
\hline $0-2$ & Acessibilidade & 0,3 & 1,8 & 1,3 & 1,4 & 0,6 & 0,7 & 2 & 1,8 & 1,9 & 1,4 & 1,4 & 1,5 & 1,9 & 2 & 1,8 & 0,3 \\
\hline $0-1$ & Existência de infra-estrutura e serviços urbanos & 0 & 1 & 0,8 & 1 & 1 & 1 & 0,2 & 0,8 & 0,8 & 0,5 & 0,7 & 0,8 & 0,5 & 0,2 & 0 & 0 \\
\hline $0-3$ & $\begin{array}{l}\text { Possibilidade de criação de espaços de } \\
\text { preservação, conservaçâ, recreação e lazer. }\end{array}$ & 2,8 & 1,7 & 2,5 & 2,2 & 2,5 & 2,5 & 1,9 & 1,4 & 1,6 & 0,8 & 1,4 & 1,6 & 0,8 & 1,5 & 3 & 3 \\
\hline & Total atribuido & 3,2 & 7,5 & 6,3 & 6 & 8,6 & 6,9 & 4,4 & 7,3 & 9 & 5,4 & 7 & 7,7 & 7,3 & 7,7 & 6,1 & 5,1 \\
\hline
\end{tabular}

Tabela 1: peso e característica de cada unidade paisagística. Fonte: Adaptado do programa da disciplina AUP-062.

Relativamente à aptidão para a urbanização, as residências situadas em encosta apresentam um valor mais baixo comparativamente às similares em fundo de vale $e$ topo de morro devido às dificuldades que o declive acentuado oferece às construções de urbanizações. A unidade que apresenta o valor mais alto é o comércio - topo de morro e o menor é o curso de água e raia olímpica, situado em fundo de vale.

A unidade que apresenta um maior potencial para a expansão urbana é a rodovia, que não obedece a nenhum critério de protecção de áreas sensíveis e foi construída em cima de cursos de água e as unidades residencial horizontal - fundo de vale e residencial vertical - tipo de morro, que apresentam tendências à sua expansão.

Quanto à contiguidade a áreas urbanizadas e vectores de urbanização é a Cidade Universitária - encosta e topo de morro que apresentam menores valores (nulos), ao contrário das residências verticais fundo de vale e topo de morro que chegam a atingir 1,8 valores em 2. A existência de infra-estruturas e serviços urbanos é nula na Cidade Universitária - encosta e toma o valor 0,8 nas unidades Cidade Universitária - topo de morro, residencial horizontal - encosta e residencial horizontal - fundo de vale. 
A característica "Possibilidade de criação de espaços de preservação, conservação, recreação e lazer" atinge o valor 2,8 na unidade paisagística Cidade Universitária encosta e é máxima na vegetação arbustiva e arbórea na encosta e em fundo de vale. No entanto, esta característica toma valores mínimos nas residências horizontais topo de morro e residências verticais - topo de morro.

Somando todos os valores, o total atribuído resulta num maior ou menor potencial de urbanização. Sendo assim, é a unidade paisagística "Residencial vertical - fundo de vale" que apresenta um maior potencial de urbanização, ao contrário da "Cidade Universitária - encosta" que apresenta o valor mais baixo para uso urbano.

A tabela seguinte apresenta os valores para a conservação da paisagem local, apresentando o resultado relativamente ao maior e menor potencial de protecção ambiental.

\begin{tabular}{|c|c|c|c|c|c|c|c|c|c|c|c|c|c|c|c|c|c|}
\hline \multicolumn{18}{|c|}{ Atribuição de valores para conservação da paisagem local } \\
\hline Peso & & \multicolumn{16}{|c|}{ Unidades de Paisagem } \\
\hline \multicolumn{2}{|r|}{ Característica } & 1 & 2 & 3 & 4 & 5 & 6 & 7 & 8 & 9 & 10 & 11 & 12 & 13 & 14 & 15 & 16 \\
\hline $0-2$ & Integridade das áreas de vegetação (biodiversidade) & 1,8 & 1,3 & 1,6 & 0,2 & 0,2 & 0,2 & 0,6 & 0,3 & 0,3 & 0,3 & 0,2 & 0,2 & 0,4 & 0 & 1,8 & 1,8 \\
\hline $0-1$ & $\begin{array}{l}\text { Possibilidade de criação de corredores ecológicos e } \\
\text { de integração de fragmentos }\end{array}$ & 1 & 1 & 1 & 0,1 & 0,2 & 0,2 & 0,8 & 0,6 & 0,7 & 0,5 & 0,4 & 0,5 & 0,5 & 0,7 & 1 & 1 \\
\hline $0-2$ & Integridade da vegetação & 1,9 & 1,5 & 1,5 & 0,5 & 0,3 & 0,4 & 0,9 & 1,2 & 1,1 & 1,2 & 1,1 & 0,8 & 0,8 & 0,1 & 1,7 & 1,5 \\
\hline $0-1$ & Integridade de rios e córregos & 0,3 & 0,4 & 0,4 & 0,1 & 0,1 & 0,1 & 0,5 & 0,2 & 0,2 & 0,3 & 0,4 & 0,2 & 0,2 & 0,5 & 0,2 & 0,2 \\
\hline $0-1$ & Valores cénicos e culturais & 0,7 & 0,7 & 0,7 & 0,8 & 0,8 & 0,8 & 0,2 & 0,7 & 0,7 & 0,7 & 0,8 & 0,8 & 0,7 & 0 & 0,7 & 0,7 \\
\hline $0-2$ & Habitats significativos para fauna & 1,9 & 1,7 & 1,7 & 0,2 & 0,2 & 0,2 & 2 & 0,5 & 0,5 & 0,5 & 0,6 & 0,6 & 0,7 & 0 & 2 & 2 \\
\hline $0-1$ & Manchas significativas de vegetação & 1 & 1 & 1 & 0,1 & 0,1 & 0,1 & 0,1 & 0,3 & 0,1 & 0,1 & 0,1 & 0,1 & 0,1 & 0 & 1 & 1 \\
\hline $0-1$ & Resiliência dos ecossistemas & 0,8 & 0,5 & 0,5 & 0,5 & 0,5 & 0,5 & 0,2 & 0,3 & 0,2 & 0,2 & 0,3 & 0,3 & 0,3 & 0 & 0,7 & 0,7 \\
\hline \multirow[t]{2}{*}{$0-1$} & $\begin{array}{l}\text { Potencial como zona de amortecimento de impactos } \\
\text { ambientais }\end{array}$ & 0,5 & 0,7 & 0,4 & 0,4 & 0,4 & 0,3 & 0,1 & 0,5 & 0,1 & 0,5 & 0,3 & 1,1 & 0,3 & 0,1 & 0,4 & 0,4 \\
\hline & Total atribuído & 9,9 & 8,8 & 8,8 & 2,9 & 2,8 & 2,8 & 5,4 & 4,6 & 3,9 & 4,3 & 4,2 & 4,6 & 4 & 1,4 & 9,5 & 9,3 \\
\hline
\end{tabular}

Tabela 2: atribuição de valores para conservação da paisagem local.Fonte: Adaptado do programa da disciplina AUP-062.

A característica relativa à integridade das áreas de vegetação (biodiversidade) toma os valores mais elevados nas unidades "Cidade Universitária - encosta" e "Vegetação arbórea e arbustiva - encosta e fundo de vale; ao contrário da "Rodovia - fundo de vale" que apresenta valores nulos e do comércio e das residenciais verticais que também apresentam valores baixos.

Continua a ser a "Cidade Universitária - encosta, topo de morro e fundo de vale" e "Vegetação arbustiva e arbórea - encosta e fundo de vale" que apresentam os valores mais elevados mas desta vez para a característica de possibilidade de criação de corredores ecológicos; e é o Comércio que apresenta uma possibilidade da criação destas estruturas mais baixa. 
Relativamente à característica integridade da vegetação, a "Cidade Universitária encosta" está muito próxima do valor máximo, e a Rodovia muito próxima do mais baixo. Ou seja, esta unidade não apresenta integridade praticamente nenhuma com a vegetação. Relativamente à integridade dos rios e córregos, é esta característica que apresenta uma média de atribuição de valores mais baixos. Isto porque o subdistrito de Butantã, apresenta uma clara deficiência de urbanização integrando e conservados os rios e córregos, sendo mesmo construídos em cima destes, rodovias e estradas. Esta situação leva a uma canalização dos rios de modo a facilitar este tipo de construção. A própria unidade "Curso de água e raia olímpica - fundo de vale" tem um valor baixo devido à ausência de integração deste com o espaço ambiente envolvente. É notável a falta de planeamento aquando da construção da marginal Pinheiros e à consideração deste curso de água como um recurso interessante e importante para toda a população.

É a unidade paisagística "Rodovia - fundo de vale" que apresenta o menor valor (zero) para a característica de valores cénicos e culturais, ao contrário do comércio e das residências verticais que apresentam valores mais altos. Quanto aos habitats significativos para a fauna, a própria Cidade Universitária apresenta valores altos mas é o curso de água que apresenta o valor máximo, ao contrário da rodovia onde o valor é nulo.

A Cidade Universitária e a vegetação arbustiva e arbórea contem as manchas mais representativas para a vegetação, contrastando com o valor da rodovia - fundo de vale. Relativamente à características "Resiliência dos ecossistemas", o comportamento das unidades na característica anterior é semelhante, ou seja, mais elevado para a cidade universitária e vegetação arbustiva e arbórea e mais baixo para a rodovia.

Quanto ao potencial de amortecimento de impactes ambientais, as residências apresentam geralmente valores baixos por serem sensíveis a catástrofes naturais e a cidade universitária - topo de morro é a que apresenta um valor mais alto.

Assim sendo, e somando os valores atribuídos a todas as unidades paisagísticas para cada uma das características, verifica-se que é a "Cidade Universitária - encosta" que tem um potencial maior para a protecção da paisagem local, e é a "Rodovia - fundo de vale" que presenta um menor potencial de protecção da paisagem. 


\section{CONCLUSÃO}

A realização deste artigo permite que trabalhos futuros tenham um planeamento mais robusto, contribuindo assim para a melhor qualidade de vida dos moradores do Subdistrito Butantã e, indirectamente, do Distrito Butantã. Assim, é de frisar a importância de um planeamento da paisagem, que deve ter em conta as unidades paisagísticas da área de estudo.

Neste âmbito, é importante discutir a importância dos SIG que facilitam e ajudam na interpretação de qualquer atributo e permite um menor gasto de recursos humanos e materiais. No entanto, aquando a realização deste trabalho, houve alguns obstáculos que impediram a avaliação totalmente correcta destas unidades. Isto porque as bases cartográficas continham alguns erros e algumas delas estavam mal georreferenciadas ou incompletas. Para além deste tipo de erros, o facto do preenchimento das tabelas de avaliação ser totalmente individual e de acordo daopinião de quem as avalia, torna essa conclusão subjectiva. Outra limitação encontrada no decorrer deste trabalho foi o facto dos usos do solo identificados não corresponderem à realidade actual, visto a informação recolhida ser um cruzamento entre mapas de 2012 (Google Earth) e de 2007 (ortofotomapas da Emplasa).

Relativamente à carta dos usos do solo do subdistrito Butantã conclui-se que é a Cidade Universitária que apresenta uma maior expressão na área de estudo e que, por isso, deve ter uma especial atenção para a sua gestão, visto poder influenciar uma maior área. Já a vegetação de mata e de capoeira deve ser conservada e mantida de modo a poder recuperar de quaisquer impactes ambientais que possam sofrer. Deste modo, é reduzida a permeabilização do subdistrito, diminuindo também as enchentes que tanto danificam meios materiais e humanos. No entanto, as residências também se apresentam em grande parte do subdistrito, acompanhadas de pouca vegetação e espaços verdes.

Quanto à avaliação das unidades paisagísticas, a que apresenta um maior potencial de urbanização é a "Residencial vertical - fundo de vale". Assim, é esta unidade que deve ter um maior investimento, tendo sempre em conta um correcto planeamento ambiental. Contrariamente, é a unidade "Cidade Universitária - encosta" que possui os menores valores para potencial de urbanização, sendo que deve acarretar uma correcta gestão aquando a urbanização da zona. 
Relativamente à atribuição de valores para a conservação da paisagem local é a "Cidade Universitária - encosta" que apresenta um registo maior, sendo por isso a que mais potencial tem para a protecção da paisagem local; assim, esta contribui para o aumento da biodiversidade e de espaço verde no Subdistrito. Contrariamente, a "Rodovia - fundo de vale" apresenta um menor potencial de paisagem, pelo que se torna menos significativa para a protecção deste parâmetro, no Subdistrito Butantã.

\section{REFERÊNCIAS BIBLIOGRÁFICAS}

Barreiros, L. (2005). Avaliação da paisagem: contributo para o planeamento da paisagem protegida. Universidade Nova de Lisboa.

Bruna, G. C., Goldemberg, J., \& Roméro, M. d. A. (2000). Metrópoles e o desafio frente ao meio ambiente (Vol. 6).

Bógus, L. M. M., \& Pasternak, S. (2009). Observatório das Metrópoles. Como anda São Paulo. Rio de Janeiro.

Castro, E. d., \& Lopes, A. (2009). Usos e Funções da Paisagem no Desenvolvimento Social: A Raia Central Portuguesa. Paper presented at the $1^{\circ}$ Congresso de Desenvolvimento Regional de Cabo Verde.

Center, G. I. (2010). Green Infrastructure Ecological Concepts. Retrieved Abril, 2012

Filho, A. J. P., Barros, M. T. L. d., Hallak, R., \& Gandú, A. W. (2004). Enchentes na Região Metropolitana de São Paulo: Aspectos de Mesoescala e Avaliação de Impactos.

Filho, B. S. S. (1998). Análise de Paisagem: Fragmentação e Mudanças. Belo Horizonte.

Forman, R., \& Godron, M. (1986). Landscape Ecology. Nova York.

Jack, A. (1995). Greenways as a planning strategy. Landscape and Urban Planning, 33(1-3), 131-155. 
Lyle, J. T. (1999). Reshaping the Built Environmental Ecology, Ethics and Economics. United States of America, Washington DC.

Magalhães, M. R. (2007). Estrutura Ecológica da Paisagem: Conceitos e Delimitação - escalas regional e municipal ( $1^{\text {a }}$ ed.).

Maricato, E. (2006). Metrópoles Brasileiras. In P. A. 2006 (Ed.).

Tucci, C. E. M. (2005). Gestão de águas pluviais urbanas. In P. d. M. d. S. Saneamento, S. N. d. S. Ambiental \& M. d. Cidades (Eds.) Available from http://www.sedur. ba.gov.br/pemapes/pdf/material_tecnico/PUBLYN2.PDF

\section{Sites pesquisados}

http://www.centrodametropole.org.br/

http://www.prefeitura.sp.gov.br/cidade/secretarias/subprefeituras/butanta/historico/

Programa da disciplina AUP-062. 